\title{
Restauración de la Iglesia de San Pedro, en Avila
}

\author{
JESUS FERNANDEZ SUAREZ y RAMON FERNANDEZ TRESGUERRES, Arquitectos \\ LUIS SOMOZA ARIAS, Aparejador
}

\section{$R E S U M E N$}

Las obras fueron realizadas en dos fases consecutivas.

En la primera consistieron en sustituir las cuatro cerchas de madera de la nave central por estructuras metálicas de celosia sobredimensionadas que continuaban por las naves laterales y terminaban en zunchos de coronación, al objeto de absorber los empujes de las bóvedas que estaban arruinando la fábrica de la iglesia. Complemento de este trabajo fue una impermeabilización muy cuidada de las cubiertas de las tres naves.

En la segunda fase se restituyeron las cubiertas de absides y sacristia a su configuración original, se rejuntaron los sillares de la torre, se abrieron los huecos que estaban cegados en su cuerpo intermedio $y$ se sustituyó el cuerpo de ladrillo en ruinas de la coronación, por otro de sillería con los nuevos huecos dimensionados de acuerdo con los machones existentes y con el doble arco de las ventanas descubiertas.

\section{$S U M M A R Y$}

The work have been carried out in two consecutive phases. Firstly the four wooden nave forms were sustituted by overdimensioned iron lattice girders, that entered the aisles and ended in a capping hoop thus allowing the absorption of the pushes from the vaults that were ruining the church fabric. Besides a careful impermeabilization of both nave and aisles roof was undertaken.

The second phase included the restoration of pases and sacristies roofs to their original configurations, both with a re-pointing of the tower's ashlers and a reopening of blinded windows in his intermediate volume. The ruined capping body made of bricks was substituted by another made of ashlers. New windows were designed according to the existent buttress and following the double arch configuration of the reopened ones.

El estilo románico, que llega a Castilla con los peregrinos de Santiago de Compostela, tiene su representación en Avila en las iglesias de San Andrés, San Segundo, San Esteban, San Pedro, San Vicente, La Magdalena, San Nicolás, Santo Tomé el Viejo y Santa María de la Cabeza.

Las de San Pedro y San Vicente empezadas en románico a finales del siglo XI, cuando Raimundo de Borgoña construía las murallas de la ciudad por encargo de su suegro Alfonso VI, se terminan, ya en el XII, con bóvedas de ojivas nervadas y en su construcción, como en las demás de esta época excepto Santa María de la Cabeza, se emplea principalmente piedra del cercano pueblo de La Colilla.

Parece ser que los efectos de los empujes de las bóvedas en San Pedro, comenzaron a producir los desplomes de sus muros poco después de terminarse el edificio, lo que obligó, según Veredas, a su consolidación en el siglo XIV, colocando contrafuertes y pináculos de granito y encuadrando el rosetón en arco del mismo material.

Según Lampérez, la bóveda del brazo mayor estaba calculada para llevar medio cañón sin ventanas, un perfecto tipo de la escuela borgoñona y por eso al hacer los huecos y dar a las cubiertas laterales la pendiente adecuada para que corrieran bien las aguas, las ventanas quedaron cortadas por su parte inferior, por lo que daban poca luz. 
Se sabe muy poco de las obras de conservación o de otra clase hechas en San Pedro hasta el siglo actual, probablemente por lo poco que se ha investigado en su archivo, que espera una labor paciente que ponga al alcance de los estudiosos los datos relacionados con la historia de su fábrica.

Gutiérrez Robledo dice que Repullés trabajaba en el templo en 1922 y Veredas habla de una restauración iniciada poco tiempo antes de escribir su libro "Avila de los Caballeros", publicado en 1935, por lo que debió ser entonces cuando se restableció la casi horizontalidad de las cubiertas laterales para dar más luz al edificio, ya que Lampérez vio en 1930 las ventanas medio tapadas. Esta escasa pendiente no se acusa vista desde la plaza, porque los semihastiales de las naves laterales lo ocultan y falsean.

En 1965, Don Anselmo Arenillas dirigió obras encaminadas a suprimir las humedades existentes y puso tablero de ladrillo hueco en sustitución del enlatado de madera en las cubiertas laterales, que es tal y como las encontramos nosotros. En el año 1967 se desmontó el rosetón.

En 1980 se inician las últimas obras de consolidación y restauración en la iglesia de San Pedro. El estado de la fábrica era de ruina incipiente, acusándose desplomes generales de los muros de cerramiento, con grietas que ponían de manifiesto los movimientos habidos y eran a su vez motivo de humedades. Los sillares estaban y siguen estando en gran parte descompuestos y sueltos, especialmente en albardillas, impostas y elementos salientes, más castigados por la acción de los agentes exteriores, como el anhídrido carbónico del aire, los gases de escape de los motores de explosión, la humedad y las vibraciones. Los nervios de las bóvedas también presentaban algunas piezas sin mortero de unión y otras totalmente sueltas.

En una primera fase de estas obras se atendió a la consolidación de la fábrica para evitar

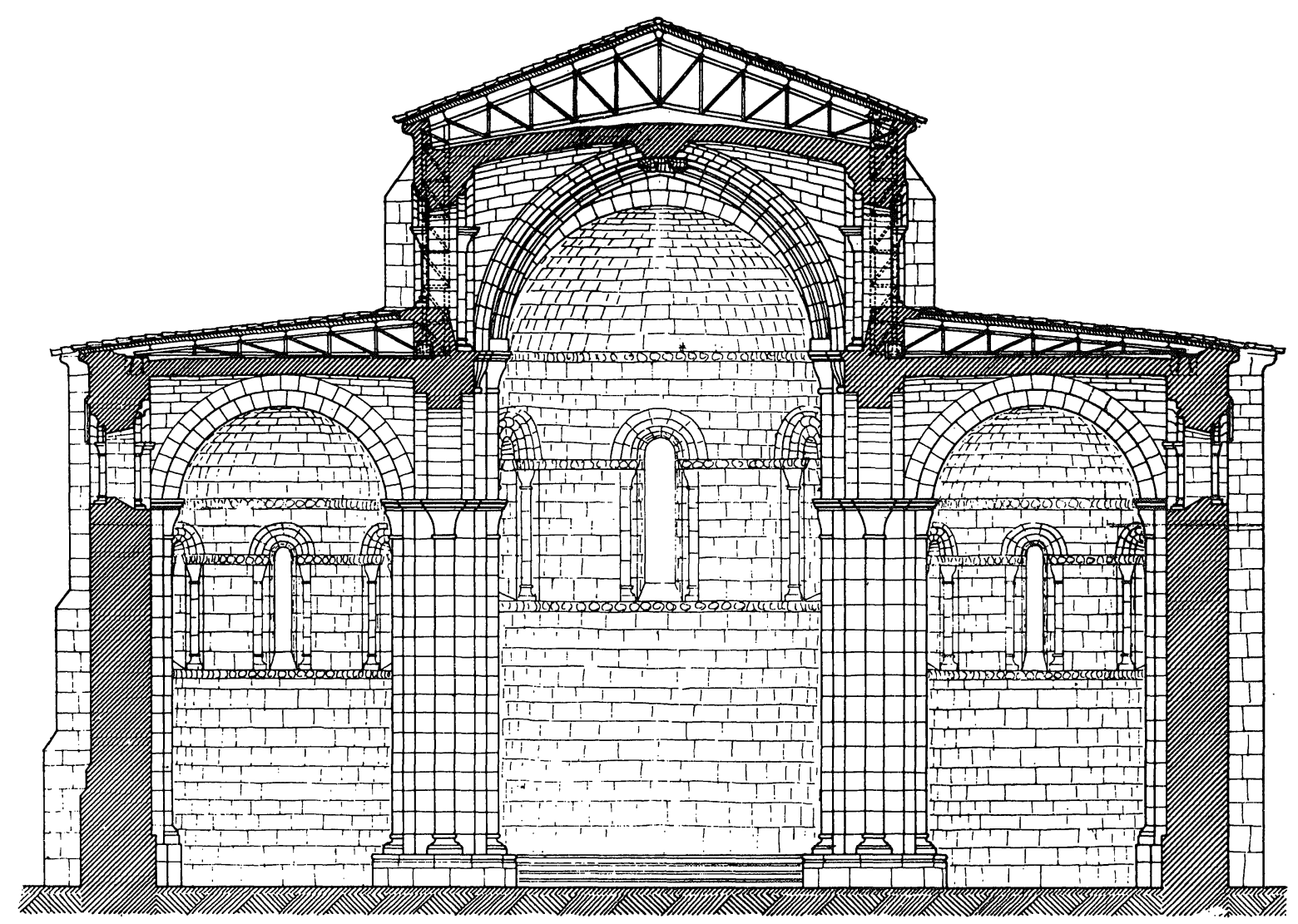

Seccion transversal. 
continuara su ruina. Para ello se absorbieron los empujes producidos por las bóvedas de las naves central y laterales colocando zunchos perimetrales de hormigón armado en la coronación de los muros de cerramiento de éstas, arriostrándolos entre sí por cuatro cerchas metálicas de celosía coincidiendo con los arcos fajones. Cada cercha lleva dos tramos verticales que van empotrados en los contrafuertes de la nave central y se prolongan en vigas que terminan en los zunchos de las naves laterales, formándose un enjaulado de gran rigidez que absorbe todos los empujes.

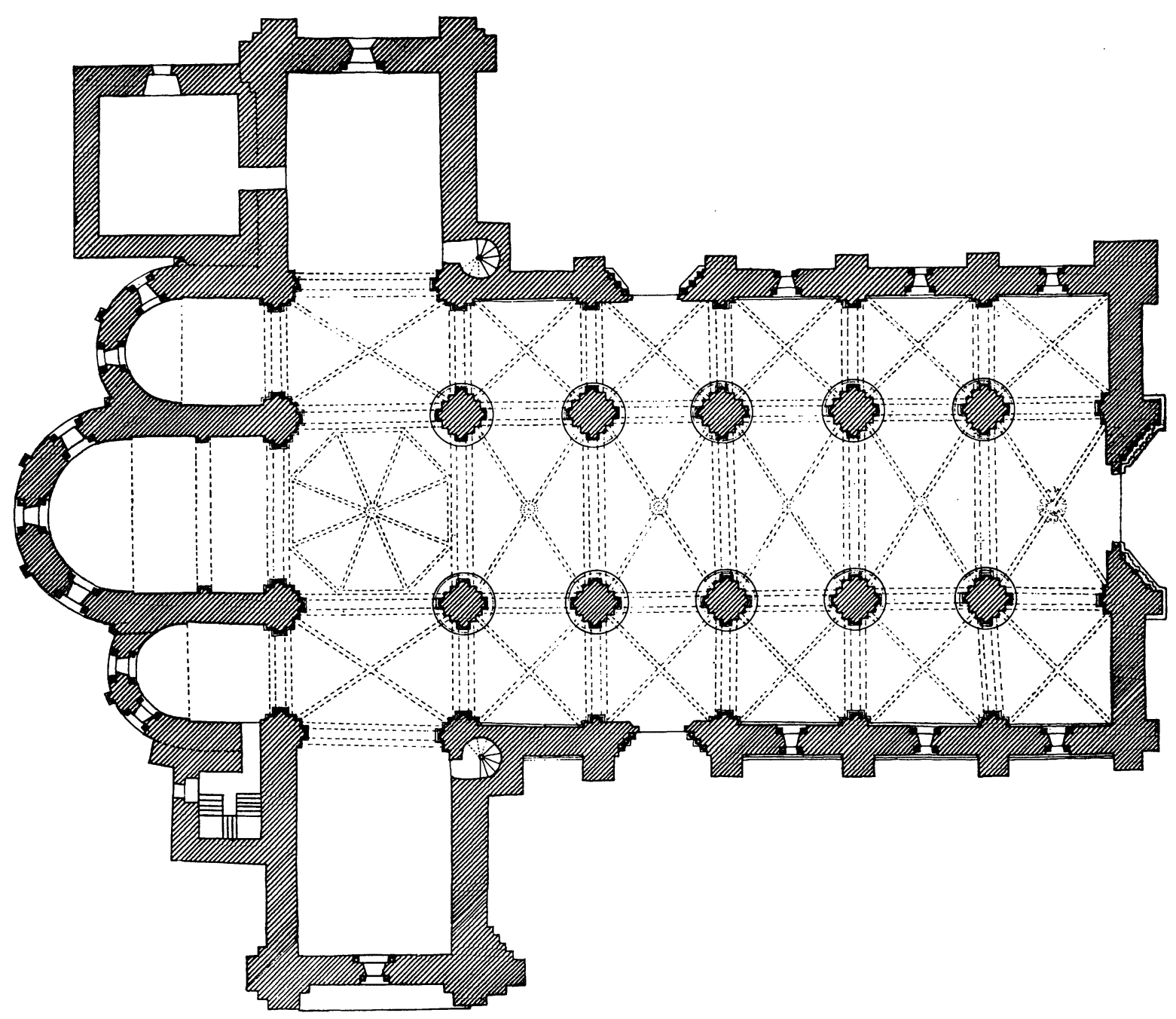

Planta.

El zuncho de coronación proyectado para la nave lateral norte se encontró ya realizado en hormigón en masa y no se juzgó conveniente demolerlo, por las vibraciones a que habría sido sometida la fábrica, por lo que se reforzó cosiéndole un perfil en $\mathrm{U}$ con redondos anclados en perforaciones practicadas en el mismo.

El cimborrio, además del zuncho perimetral, se ha reforzado con una cáscara de hormigón armado con mallazo por su trasdós.

Complemento de estos trabajos fue la construcción en la nave central de una nueva cubierta de tablero cerámico apoyado en correas metálicas en la que se ha cuidado su impermeabilización. En las cubiertas laterales se aprovechó el tablero de ladrillo hueco que se encontraba en perfecto estado y se impermeabilizó convenientemente, colocando baberos de plomo y doblando las tejas canales en las zonas de gotereo. El repaso de las juntas de los nervios de las bóvedas y la plementeria de las tres naves, completó la obra realizada en la primera fase. 
Estas obras obligaron a desmontar los contrafuertes de la nave central para empotrar en ellos parte de la estructura, por lo que hubo que proceder al apeo total por tramos de las naves central y laterales, así como a la colocación provisional de tirantes formados por barras calibradas dotadas de tensores, que atravesaban los muros de cerramiento terminando en tableros de madera para reparto de los esfuerzos. El piso de madera de la iglesia no ofrecía suficiente seguridad para resistir el apoyo de los andamios de apeo en plena carga, por lo que hubo que levantar el entarimado en las zonas que servian de base al mismo, circunstancia que se aprovechó para renovar el resto del pavimento por cuenta de la parroquia.

En la segunda fase de estas obras, finalizada en Diciembre de 1982, se ha atendido a restablecer a su primitiva configuración las cubiertas de los ábsides y sacristía, a reponer algunas piezas de cornisas y canecillos, a repasar las vidrieras y especialmente a restaurar la torre del campana-

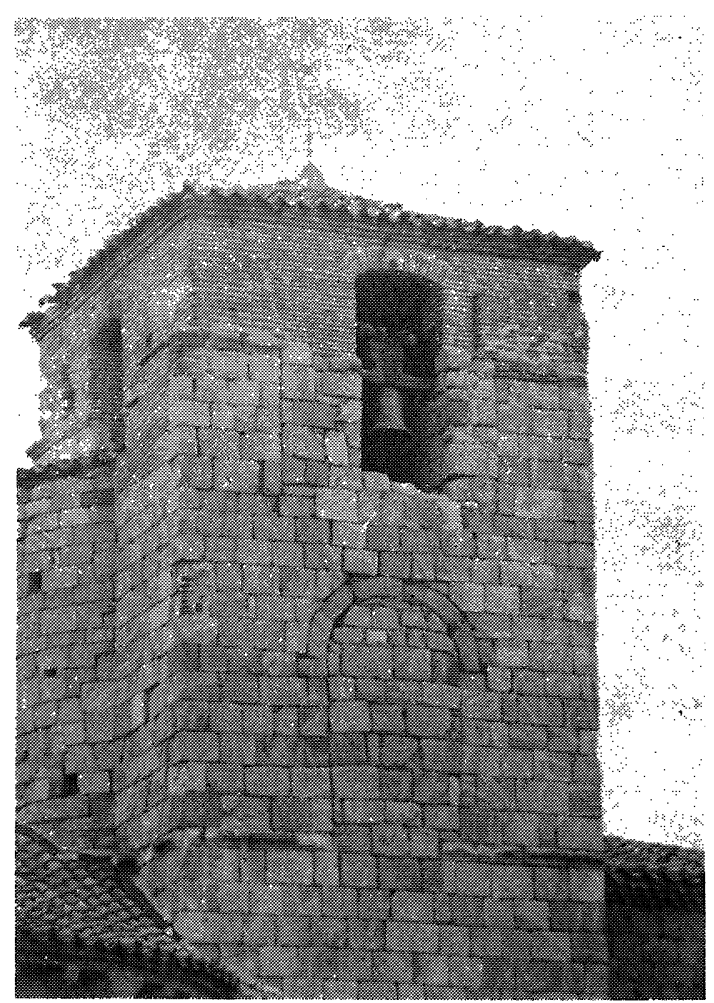

Fig. 1.-Cuerpos superior e intermedio de la torre antes de la restauración.

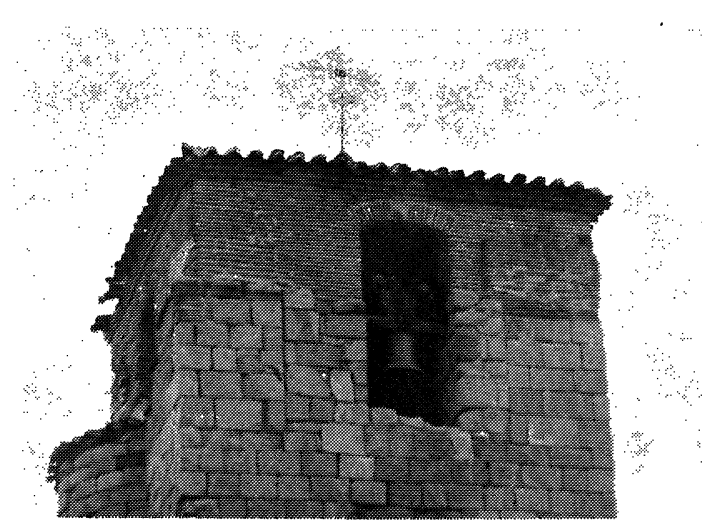

Fig. 2.-Machones de silleria en el cuerpo superior acusando el hueco existente con anterioridad.

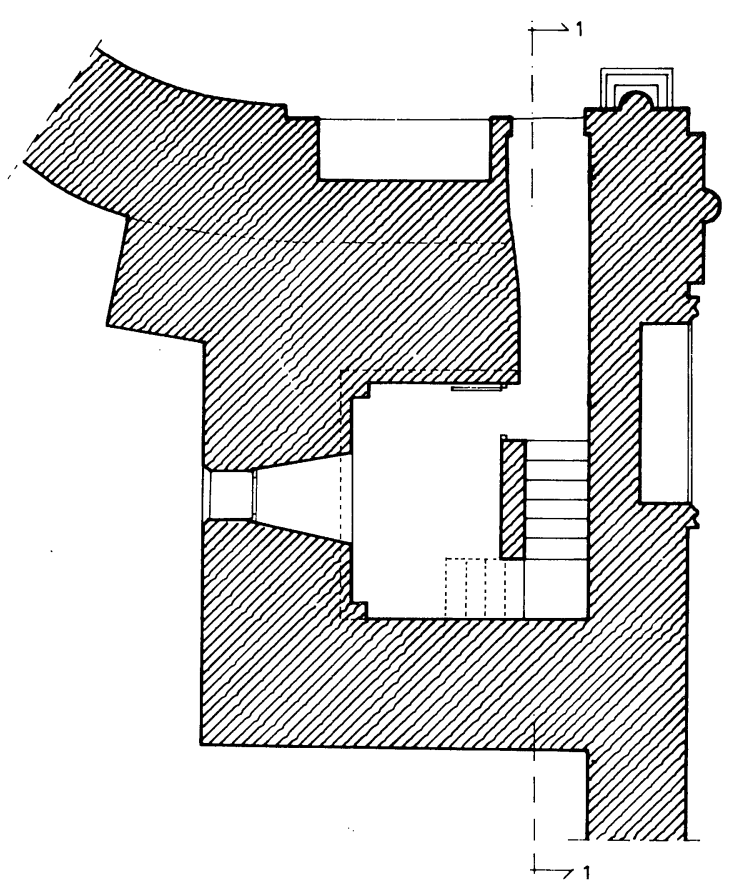

Sección por A.

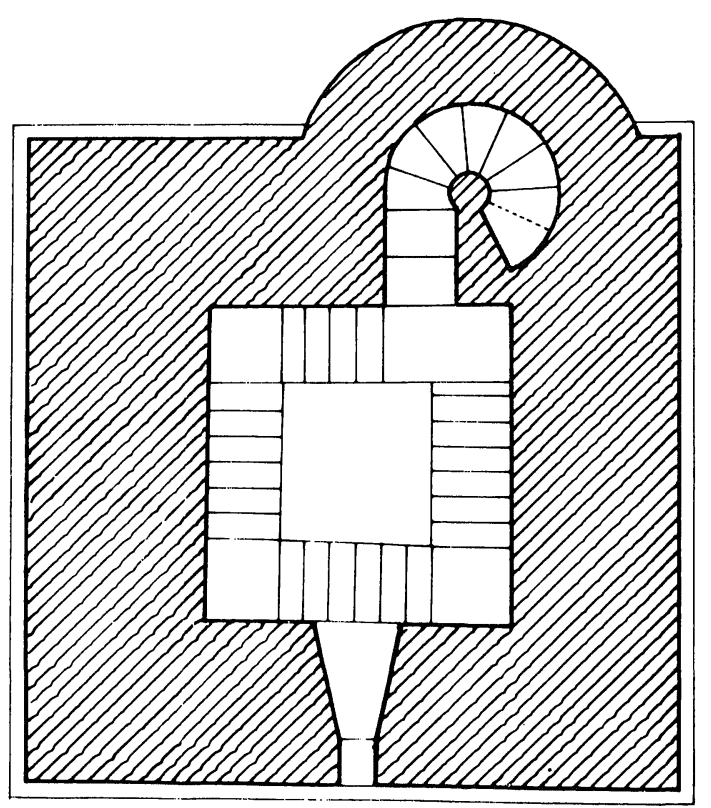

Sección por B. 
rio que estaba muy erosionada con sillares desgastados y sueltos, tanto en el zócalo, como en el resto de la torre y sustituir el remate de ladrillo del cuerpo superior por otro de silleria.

La existencia de dos machones laterales de silleria en el cuerpo alto de la torre, perfectamente definidos, separados 2,88 metros entre sí, probaban la existencia de un hueco o la intención de hacerlo, que nos condujo a la solución dada entre las posibles que podían admitirse, tratando de acercarnos al probable aspecto original del monumento, del que no había más información sobre su torre que la que podía leerse en sus piedras. Se adopta la solución de dos ventanas en cada fachada, tan frecuente en el románico, ya que una sola hubiera sido de exageradas proporciones. Resultan asi dos huecos con 1,14 metros de luz y arcos de medio punto y machón central de 0,60 metros.
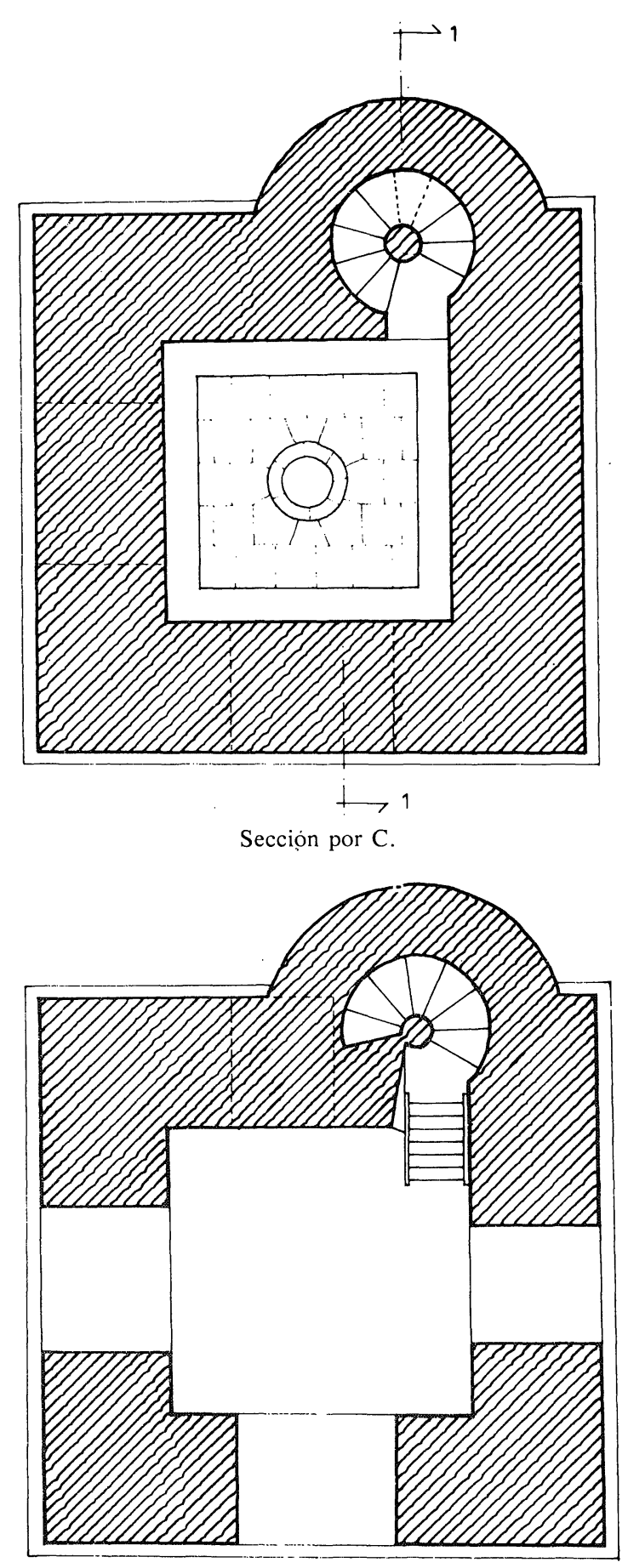

Seccion por $\mathrm{D}$.

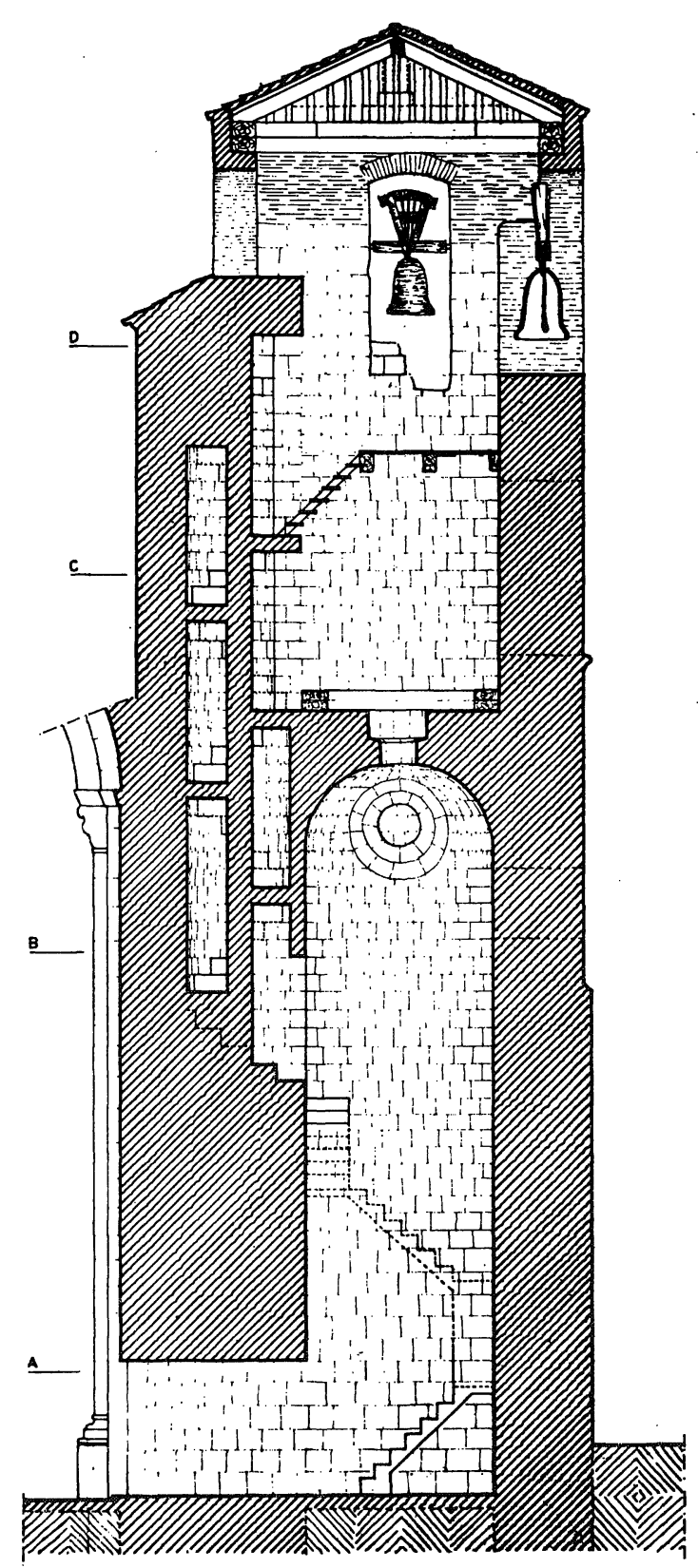

Torre del campanario. 


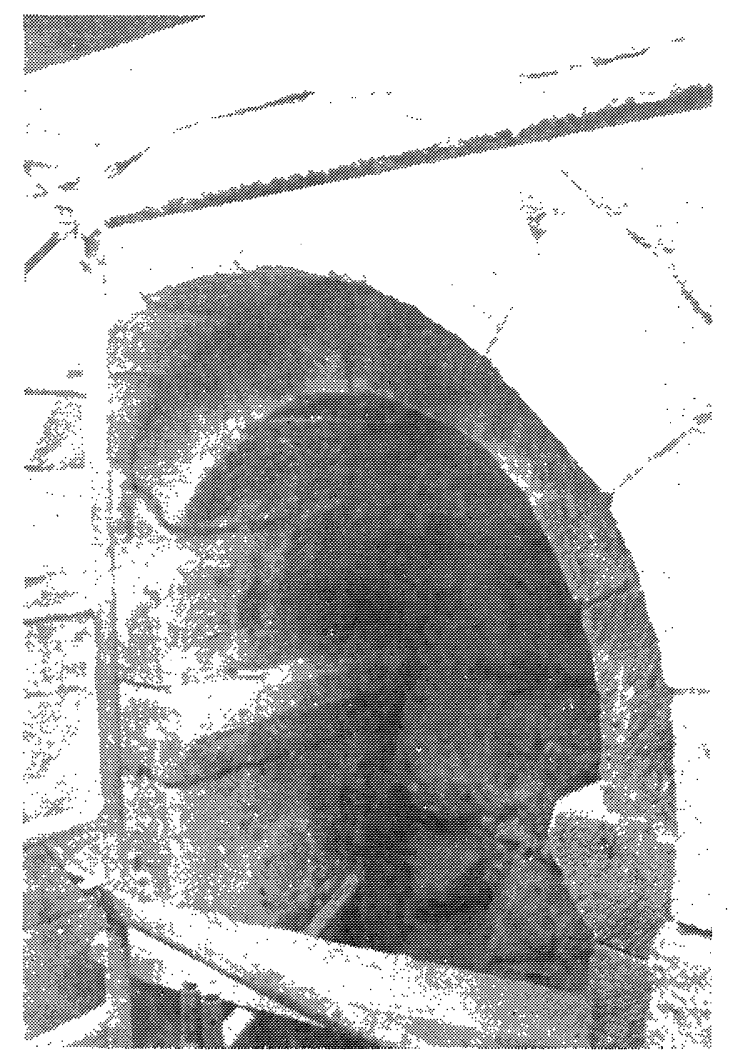

Fig. 3.-Calado de un ventanal en el cuerpo intermedio.

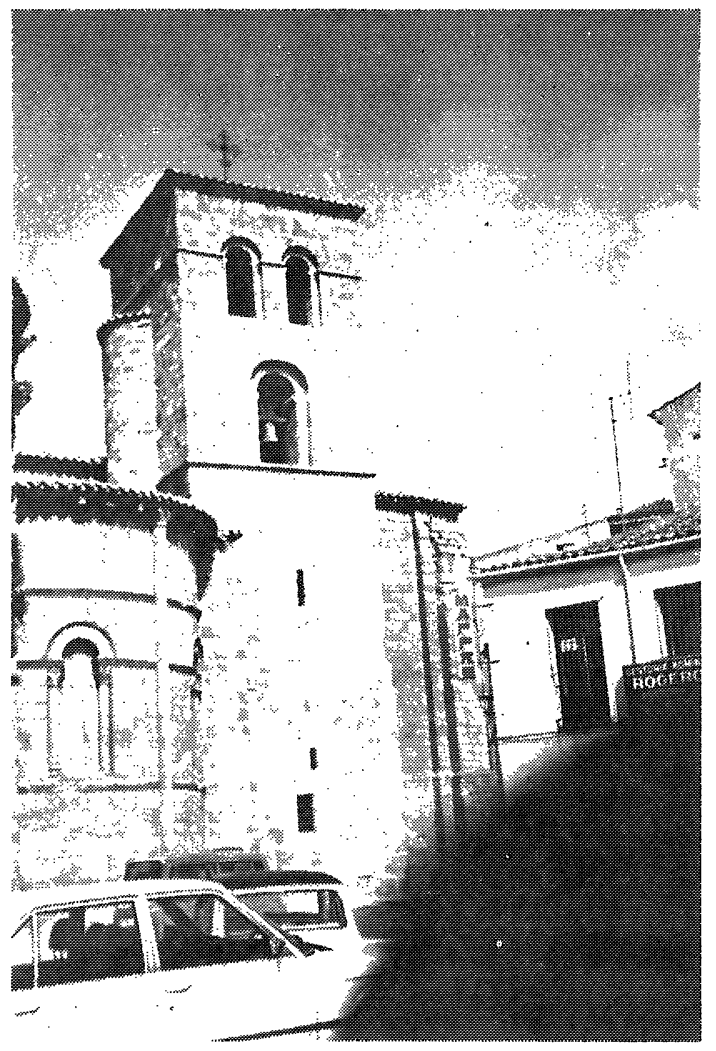

Fig. 5.-Después de la restauración.

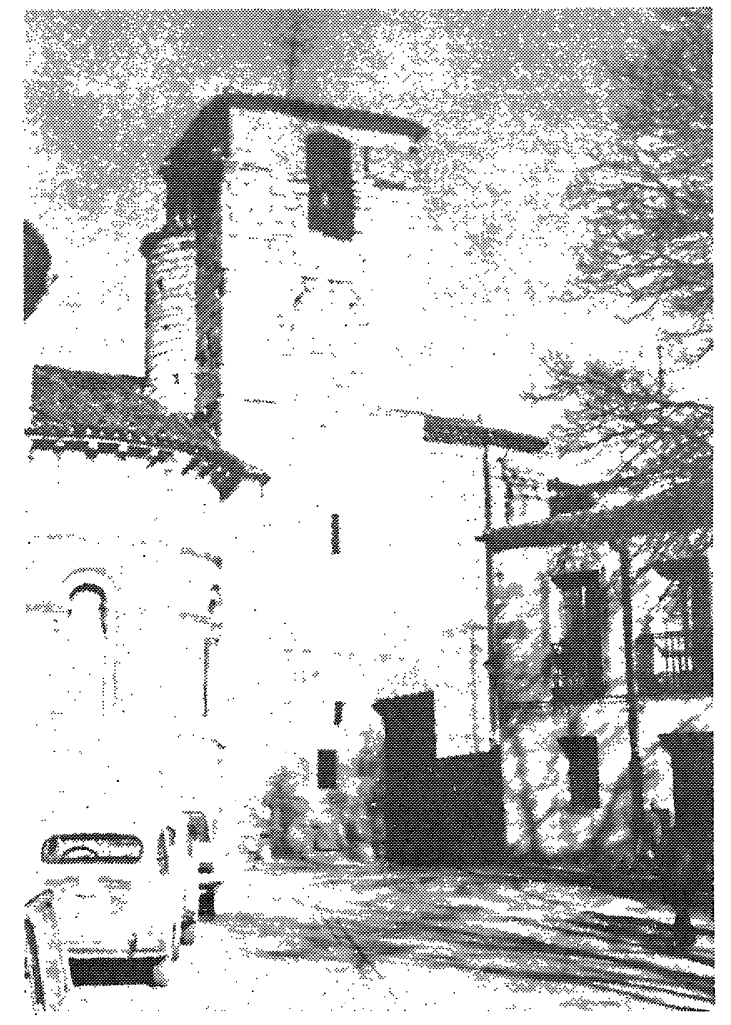

Fig. 4.-Antes de la restauración.

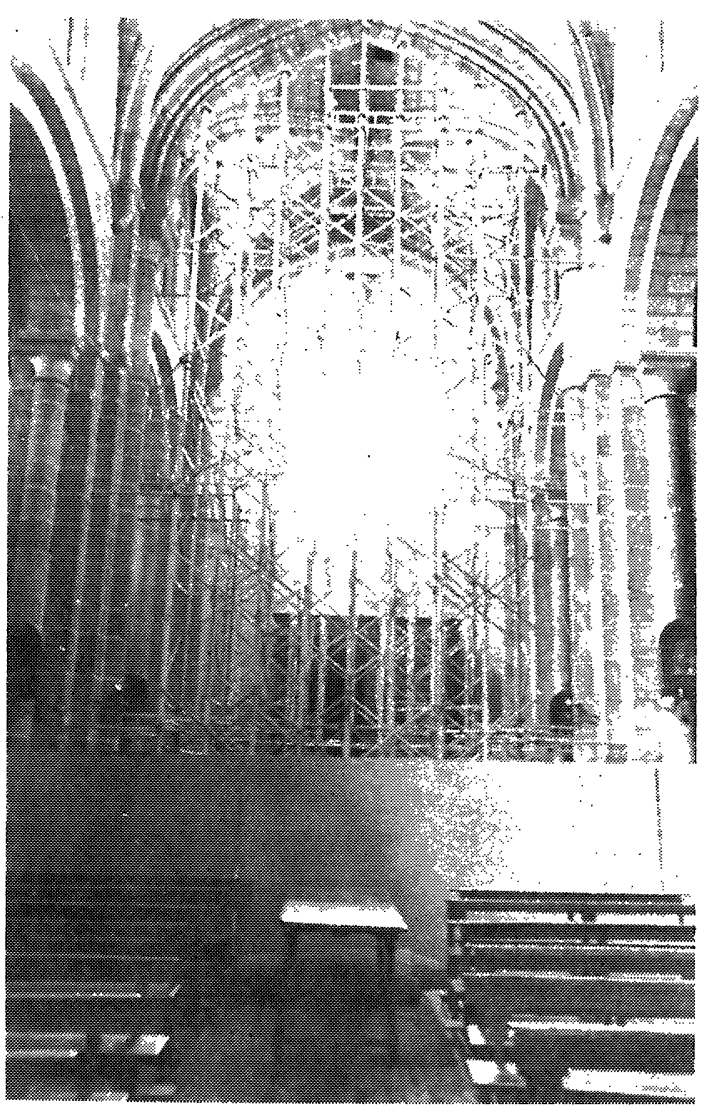

Fig. 6.-Estructura de apeo y tirantes. (Foto Lumbreras). 
El antiguo remate de la torre, hecho en ladrillo y mal conservado, constituía un cuerpo extraño y pobre en el conjunto, realizado sin duda como solución más fácil y económica, pero que no podia considerarse como definitiva, por lo que fue sustituida por sillería procedente de La Colilla, como el resto de la fábrica.

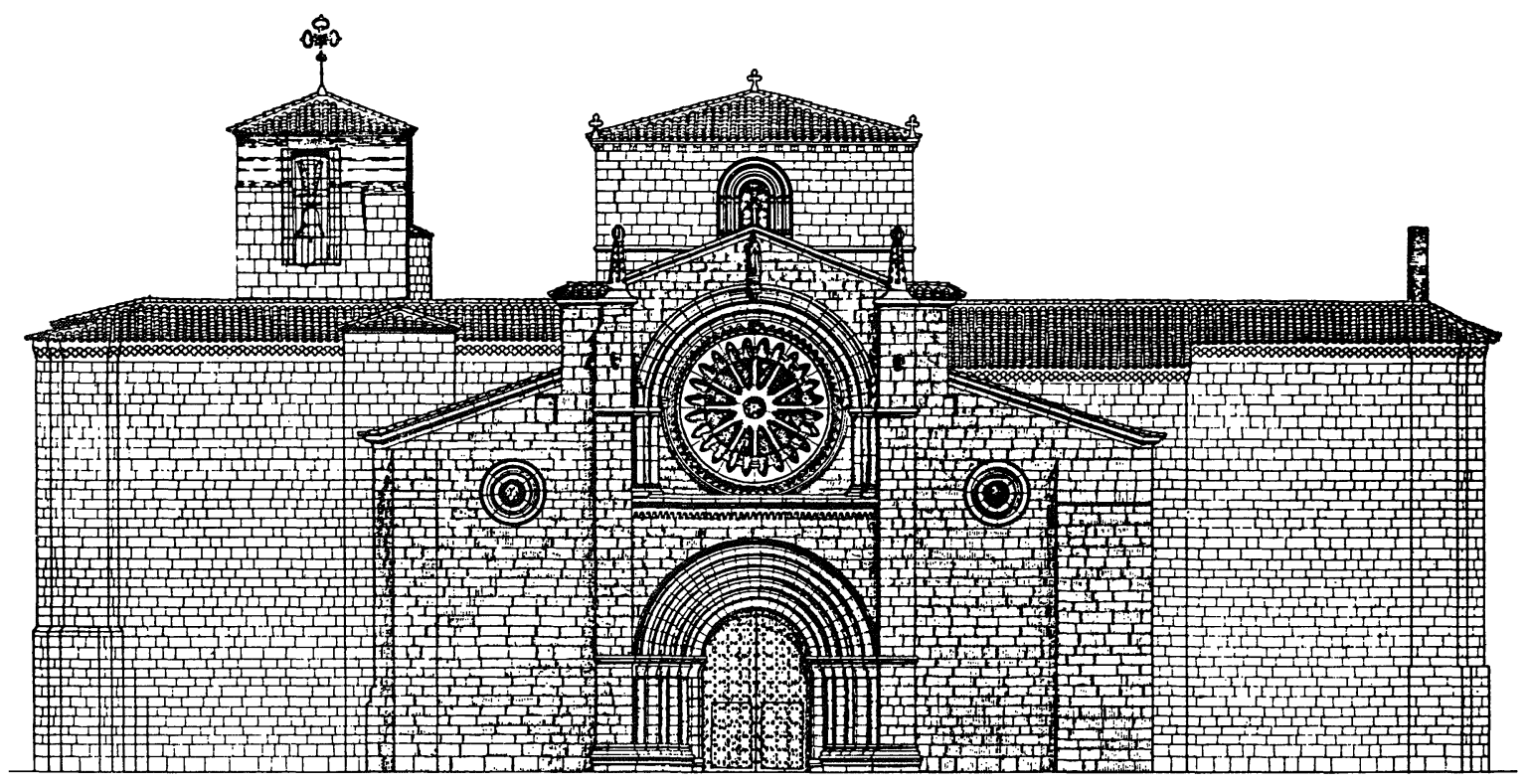

Alzado Oeste Imafronte.

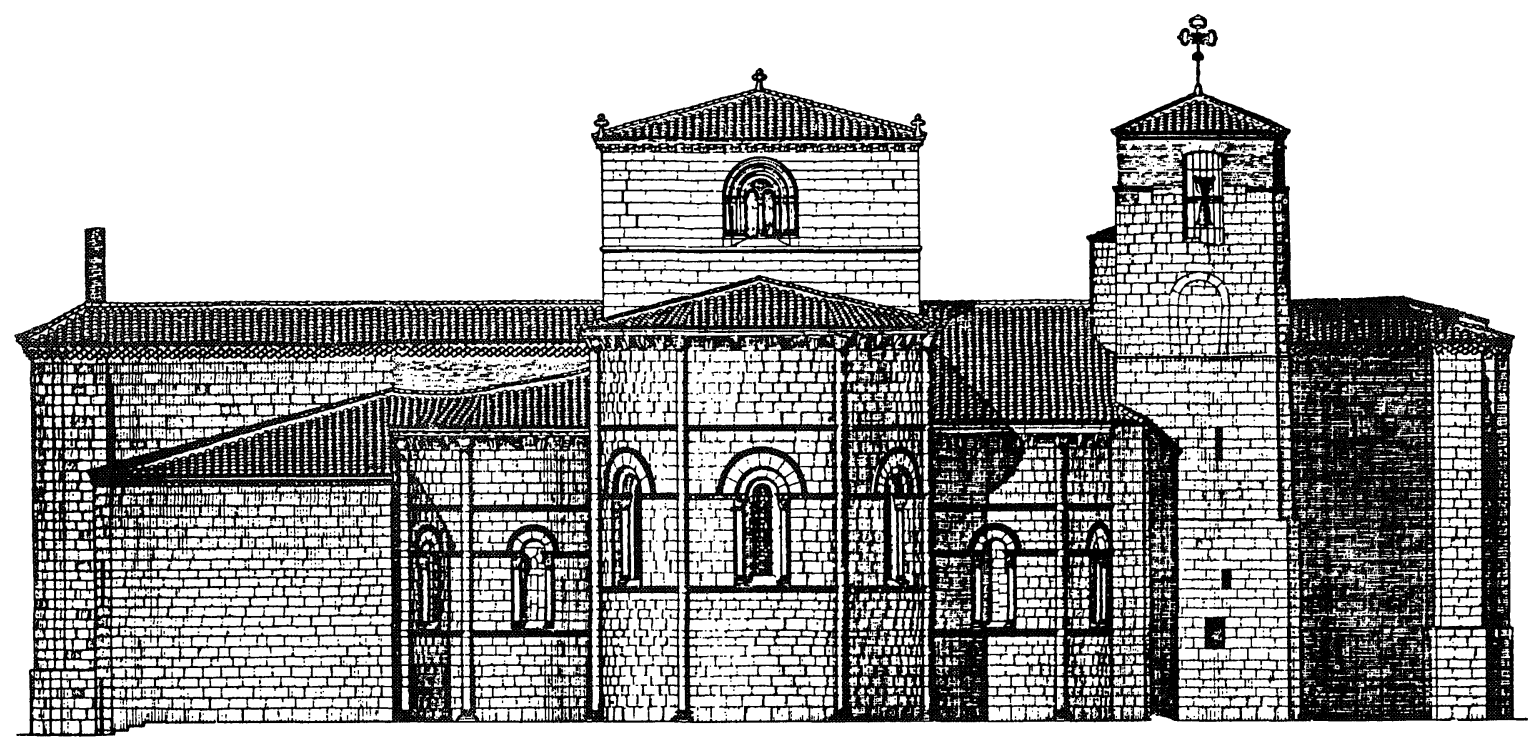

Alzado Este antes de las obras.

Los ventanales del cuerpo intermedio de la torre aparecían cegados, por lo que se pensó en dejarlos así con el cerramiento remetido para que se acusara mejor con sus sombras el juego de volúmenes, pero al encontrarlos perfectamente calados, y terminados en sus jambas y sofitos se procedió a su total apertura. Y al aparecer en ellas un arco doblado de medio punto, se repitió esta disposición en los nuevos ventanales del cuerpo superior. 
Se hicieron calicatas para examinar la cimentación de la torre, encontrándola en buenas condiciones. El zócalo de sillería tosca de granito se saneó cajeando a puntero y retacando con piedra análoga, las zonas que estaban parcheadas con ladrillo y mortero. Finalmente se hizo un rejuntado y retundido de toda la torre sustituyéndo los sillares más desmoronados, rotos o exfoliados.

Como es preceptivo, las soluciones propuestas para las cubiertas de ábsides y sacristía, del doble ventanal en la torre y la sustitución de la fábrica de ladrillo por silleria, merecieron la aprobación correspondiente de la Subdirección General de Restauración de Monumentos del Ministerio de Cultura, organismo que corre a cargo de estas obras.

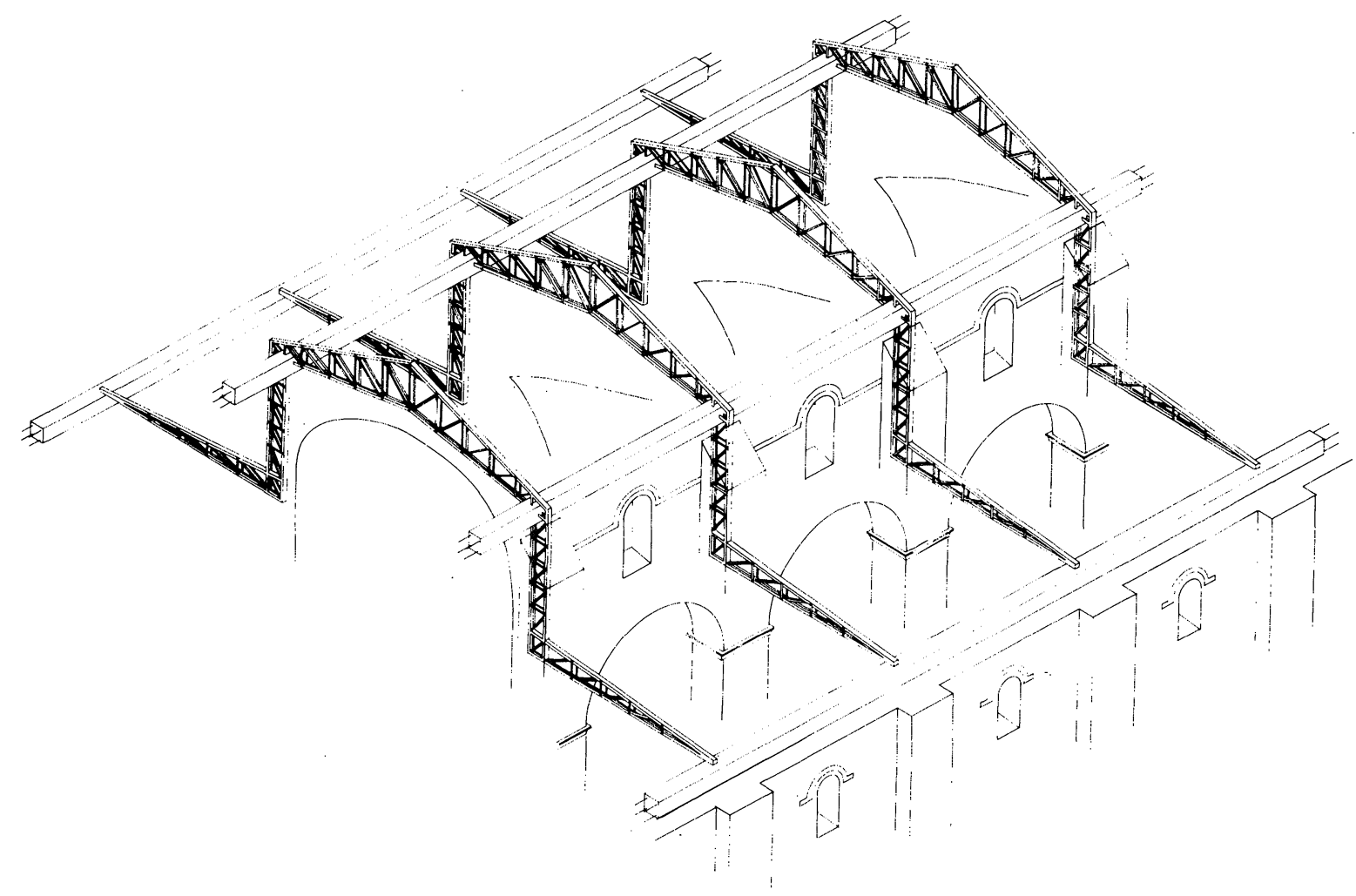

Estructura de la cubierta.

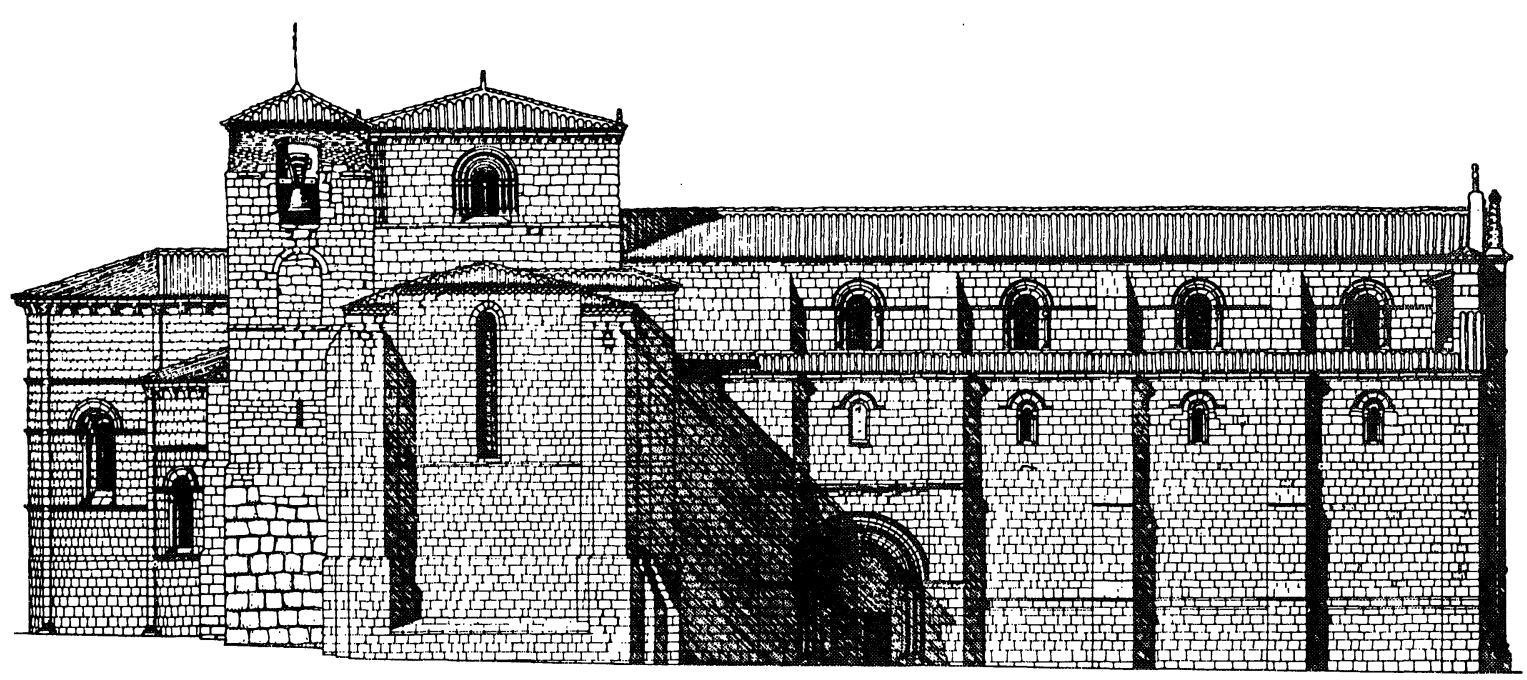

Alzado Norte. 
Según puede apreciarse fácilmente por el mal estado exterior de la fábrica, es necesario el continuar la renovación de numerosos sillares en mal estado y el rejuntado y llagueado de gran parte de la misma.

Terminamos esta breve reseña de las obras efectuadas en San Pedro llamando la atención sobre la conveniencia de desviar la circulación rodada de las inmediaciones de la iglesia, al menos de los vehículos pesados que circulan a dos metros del brazo norte del crucero y que con sus gases de escape y las vibraciones que producen a su paso, contribuyen grandemente al deterioro de la piedra.

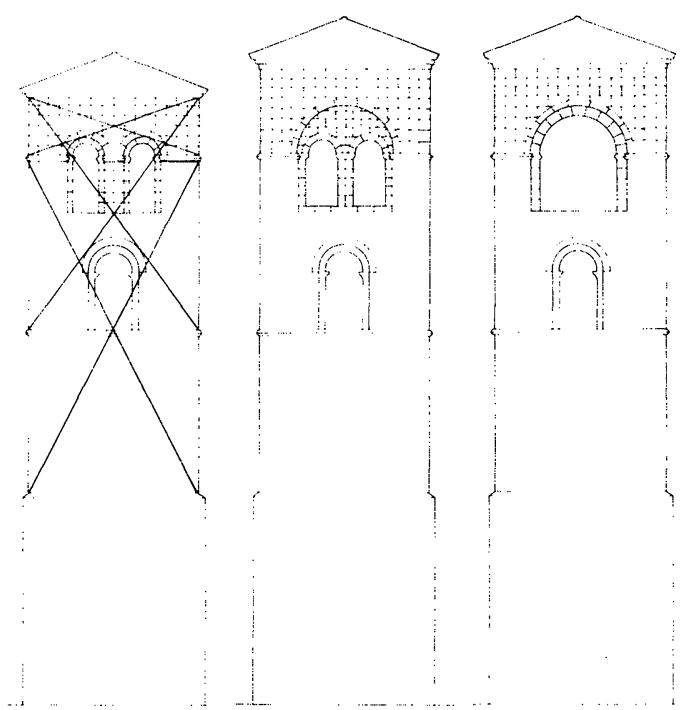

Posibles soluciones.

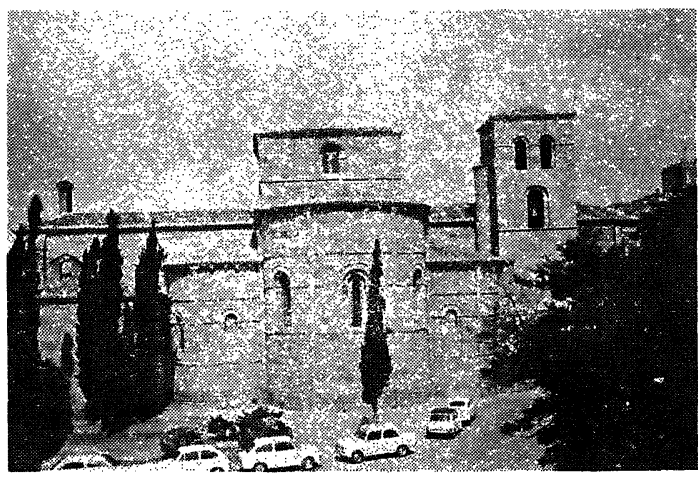

Fig. 7.-Fachada a levante, mostrando las nuevas cubiertas de los ábsides y la torre.

También deben arbitrarse las ordenanzas necesarias para que no vuelvan a autorizarse obras en las proximidades de monumentos, como las que están haciéndose a diez metros de San Pedro, con tres sótanos excavados en la misma roca que sustenta la iglesia y cuyo vaciado, hasta más de trece metros de profundidad bajo la rasante de la acera, empleando martillos perforadores y explosivos, forzosamente han tenido que incidir en la conservación de la piedra y en la estructura del edificio, acelerando su envejecimiento.

El coste total de las obras ha sido de 24 millones de pesetas. 